\title{
Tuning of Photoluminescence and Antibacterial Properties of ZnO Nanoparticles through Sr Doping for Biomedical Applications
}

\author{
R. Karthick $\mathbb{D},{ }^{1}$ P. Sakthivel $\mathbb{D},^{2}$ C. Selvaraju $\mathbb{D}^{3},{ }^{3}$ and Mosae Selvakumar Paulraj $\mathbb{D}^{4}$ \\ ${ }^{1} P G$ Department of Physics, Srinivasan College of Arts and Science, Perambalur - 621 212, Tamil Nadu, India \\ ${ }^{2}$ Department of Physics, Centre for Materials Science, Faculty of Engineering, Karpagam Academy of Higher Education, \\ Coimbatore, 641021 Tamil Nadu, India \\ ${ }^{3}$ Department of Physics, V.S.S. Govt. Arts College, Pulankurichi, 630405 Tamil Nadu, India \\ ${ }^{4}$ Science and Math Program, Asian University for Women, Chattogram, Bangladesh
}

Correspondence should be addressed to P. Sakthivel; sakthi1807@gmail.com and Mosae Selvakumar Paulraj; p.selvakumar@auw.edu.bd

Received 9 August 2021; Revised 1 November 2021; Accepted 6 November 2021; Published 17 November 2021

Academic Editor: Angelo Taglietti

Copyright (c) 2021 R. Karthick et al. This is an open access article distributed under the Creative Commons Attribution License, which permits unrestricted use, distribution, and reproduction in any medium, provided the original work is properly cited.

\begin{abstract}
Sr-doped $\mathrm{ZnO}$ nanoparticles have been synthesized using a soft chemical method. The doping ratio of Sr is varied in the range of 0 at.\%, 3 at.\%, and 5 at.\% to 7 at.\%. X-ray diffractograms revealed that the samples had hexagonal (wurtzite) structure without a trace of any mixed phase. The average crystallite size of the nanoparticles (NPs) ranged from 39 to $46 \mathrm{~nm}$. The average crystallite size was increased for the initial doping ( 3 at.\%) of Sr ions, and further increase in the doping ratio reduced the particle size due to some distortion produced in the lattice. The surface morphology of the samples and structure of the NPs were investigated using FESEM (Field Emission Scanning Electron Microscopy) and TEM (Transmission Electron Microscopy) pictures, respectively. EDX (energy-dispersive X-ray) spectroscopy confirmed the presence of strontium ( $\mathrm{Sr}$ ) in the host lattice. Photoluminescence and X-ray diffraction confirmed that the dopant ions replace some of the lattice zinc ions and that $\mathrm{Sr}^{2+}$ and $\mathrm{Sr}^{3+}$ ions coexist in the $\mathrm{ZnO}$ lattice. The Sr-doped $\mathrm{ZnO}$ exhibited violet and blue luminescence spectra at $408 \mathrm{~nm}$ and $492 \mathrm{~nm}$, respectively. $\mathrm{ZnO}: \mathrm{Sr}$ nanoparticles showed increased antibacterial activity against one gram-positive as well as one gram-negative bacteria.
\end{abstract}

\section{Introduction}

Zinc oxide $(\mathrm{ZnO})$ is a II-VI semiconductor with a wide band gap $(3.37 \mathrm{eV})$ that has a lot of uses in optoelectronics [1-3]. $\mathrm{ZnO}$ is identified as a multifunctional material due to its diverse applications in various fields [4]. Luminescencebased approaches have recently attracted huge attention due to their broad potential in domains including optical devices and biological applications like displays and anticounterfeiting [5-7]. Luminescent inorganic nanoparticles, in particular, have piqued interest due to their enormous potential uses and for fundamental science study in a variety of domains [8]. The electrical and optical capabilities of variously shaped $\mathrm{ZnO}$ nanowires and nanoparticles have been utilized for a variety of intriguing applications, including light-emitting diodes, phosphors, solar cells, nanolasers, electrical generators, and biosensors [1, 9-14]. Bulk $\mathrm{ZnO}$ is also the most used photocatalyst for water purification because it is more efficient and less expensive than $\mathrm{TiO}_{2}$ [15-17]. It is very interesting to create a high-crystalline $\mathrm{ZnO}$ film in large quantities at low temperatures $\left(\leq 90^{\circ} \mathrm{C}\right)$ $[18,19]$. To increase the performance of $\mathrm{ZnO}$, the majority of studies have used these strategies. Nanoparticles and nanowires of various shapes are frequently synthesized, and their optical and electrical properties have been demonstrated for a wide range of applications, including [9-14]. The photoluminescence and antibacterial efficiency of $\mathrm{ZnO}$ can be improved by doping with transition metals, rare earth elements, alkaline elements, and noble metals. Doping alkaline earth metals with $\mathrm{ZnO}$ causes lattice defects due to charge 


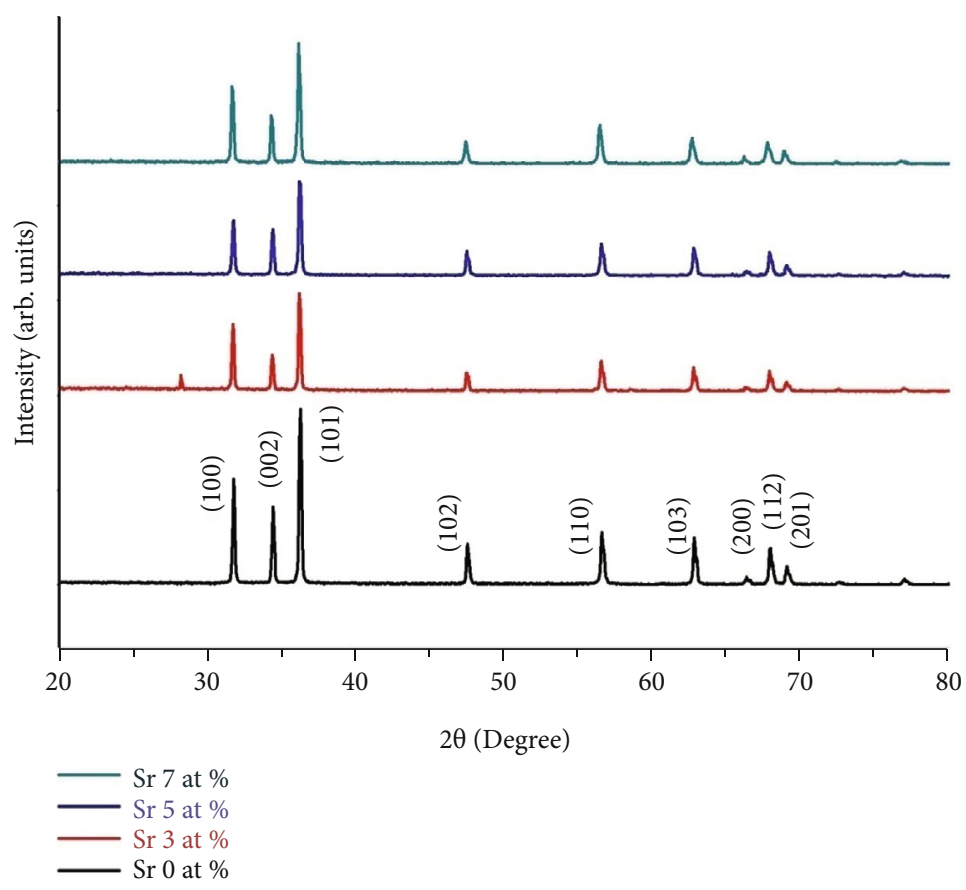

FIgURE 1: XRD patterns of undoped and Sr-doped $\mathrm{ZnO}$ nanoparticles.

compensation and ionic radius variation between the host and dopant ions $\left(\mathrm{Mg}^{2+}, \mathrm{Ba}^{2+}, \mathrm{Sr}^{2+}\right.$, etc. $)$ and $\mathrm{Zn}^{2+}$, which can boost antibacterial activity, according to a literature report. In this study, we have used a simple soft chemical approach to successfully synthesize improved luminous strontium-doped $\mathrm{ZnO}$ nanoparticles, which have the potential to improve the efficiency of optical applications. Such nanoparticles provide new avenues for embedding oxide nanoparticles on $\mathrm{ZnO}$ to promote a wide range of fundamental and advanced phenomena. Though there are some works for the investigation of optical and antibacterial activity of $\mathrm{ZnO}$ nanoparticles and SR-doped $\mathrm{ZnO}$ nanoparticles, the investigation of structural, optical, and antibacterial behaviour of Sr-doped $\mathrm{ZnO}$ is still scanty. As $\mathrm{ZnO}$ nanoparticles play a vital role in antibacterial activity, we attempted to verify the variations in the impact by introducing $\mathrm{Sr}$ ions in the $\mathrm{ZnO}$ lattice. In this article, the structural, morphological, elemental, opti$\mathrm{cal}$, and antibacterial activities of $\mathrm{ZnO}$ nanoparticles were analyzed with the influence of $\mathrm{Sr}$ ion incorporation.

\section{Materials and Methods}

2.1. Preparation of the Sample. Sigma-Aldrich provided analytical-grade zinc acetate dihydrate $\left(\mathrm{Zn}\left(\mathrm{CH}_{3} \mathrm{COO}\right)_{2} \cdot 2 \mathrm{H}_{2} \mathrm{O}\right)$, strontium nitrate $\left(\mathrm{Sr}\left(\mathrm{NO}_{3}\right)_{2}\right)$, and $\mathrm{NaOH}$. All of the compounds utilized in this study were of analytical grade and were not purified further. The $\mathrm{ZnO}$ : Sr nanoparticles were made using a simple soft chemical approach described in a previous paper [20]. In $200 \mathrm{~mL}$ of deionized water, $0.2 \mathrm{M}$ zinc acetate dihydrate was dissolved. The solution was continually agitated with a magnetic stirrer until it became homogenous. As a dopant of precursor, strontium nitrate was served at concentrations of 0 , 3, 5, and 7 at.\%, respectively. The $0.97 \mathrm{~mol}$ of zinc acetate and $0.3 \mathrm{~mol}$ of strontium nitrate were taken in a separate beaker. $1 \mathrm{~mol}$ of sodium hydroxide was taken in another beaker and
TABLE 1: Structural parameters of pure and Sr-doped $\mathrm{ZnO}$ nanoparticles.

\begin{tabular}{|c|c|c|c|c|c|c|}
\hline \multirow{2}{*}{$\begin{array}{l}\text { Sr doping } \\
\text { level (at.\%) }\end{array}$} & \multicolumn{2}{|c|}{$\begin{array}{c}\text { Lattice } \\
\text { constants }^{*}(\AA)\end{array}$} & \multirow[t]{2}{*}{$2 \theta$} & \multirow[t]{2}{*}{$\begin{array}{l}\text { FWHM } \\
\qquad(\beta)\end{array}$} & \multirow[t]{2}{*}{$\begin{array}{c}D \\
(\mathrm{~nm})\end{array}$} & \multirow[t]{2}{*}{ Microstrain } \\
\hline & $a$ & $c$ & & & & \\
\hline 0 & 3.2701 & 5.2112 & 36.27 & 0.199 & 41.9 & 8.28 \\
\hline 3 & 3.2548 & 5.2034 & 36.25 & 0.183 & 45.5 & 7.61 \\
\hline 5 & 3.2523 & 5.2109 & 36.25 & 0.215 & 38.9 & 8.90 \\
\hline 7 & 3.2525 & 5.2119 & 36.25 & 0.210 & 39.8 & 8.70 \\
\hline
\end{tabular}

dissolved. To synthesize Sr-doped $\mathrm{ZnO}$ materials, the dissolved solutions were added in a common beaker under magnetic stirring with rpm 400 per min. All the chemical solutions were taken as per the targeted stoichiometry ratio.

To maintain the $\mathrm{pH}$ of the starting solution at 8 , the mixed solution was agitated at $85^{\circ} \mathrm{C}$ for 2 hours and then maintained at room temperature for roughly 24 hours without being disturbed. The residual ions were eliminated when the white solid precipitate was filtered out. The end-product was washed with DI water and ethanol. Before characterization, the produced samples were calcined at $570^{\circ} \mathrm{C}$ for 3 hours using a tubular furnace (Make \& Model: Compact).

2.2. Material Identification. The crystal structure was determined using a PANalytical-PW 340/60 X'pert PRO X-ray diffractometer with $\mathrm{Cu}-\mathrm{K}$ radiation (1.5406) and a scanning rate of $0.02 \%$ sec. Transmission Electron Microscopy (TEM, Hitachi H-7100), Field Emission Scanning Electron Microscopy (FESEM) (Hitachi SU8000), and energy dispersive X-ray (EDX) analysis were used to examine the sample's morphology and elemental composition (model: JEOL-JSM 6390 with attachment INCA-Penta FETX3 OXFORD). The spectrofluorometer 


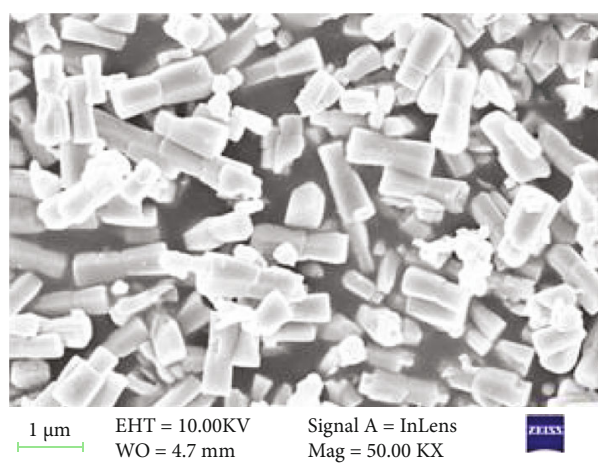

(a)

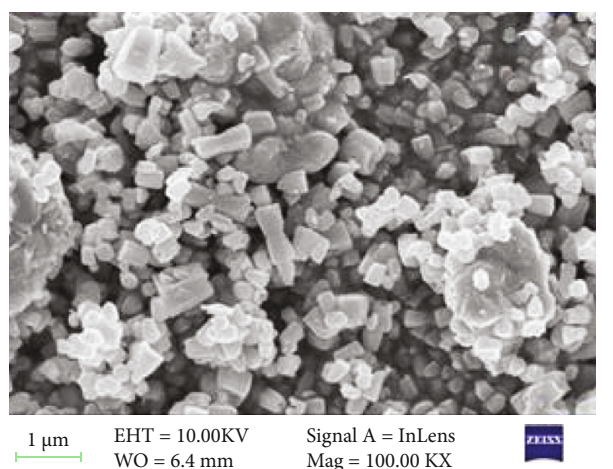

(c)

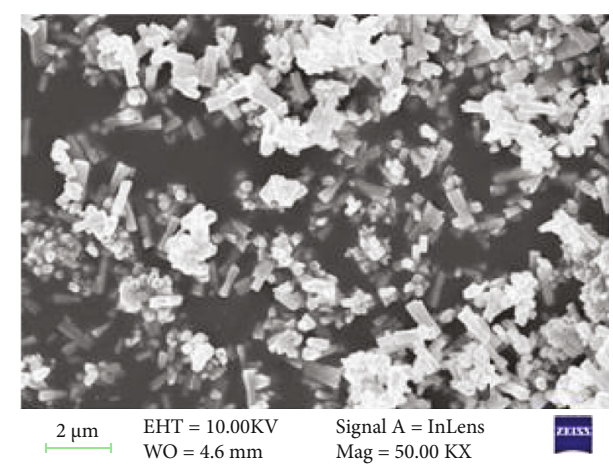

(b)

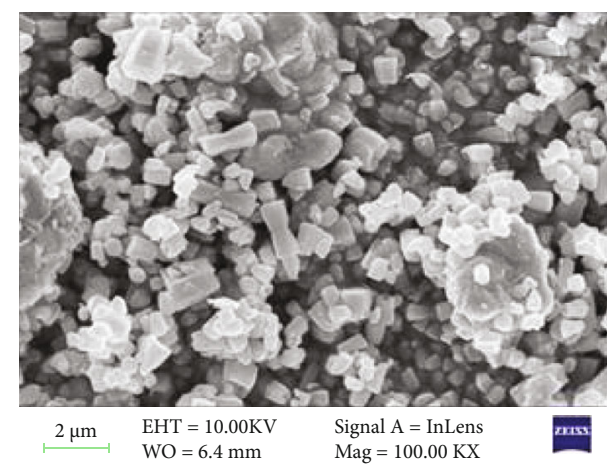

(d)

Figure 2: (a-d) FESEM images of pure and Sr-doped ZnO nanoparticles: (a) undoped, (b) 3 at.\%, (c) 5 at.\%, and (d) 7 at.\%.

(Jobin Yvon FLUROLOG-FL3-11) was used to examine photoluminescence (PL) spectra.

2.3. Measurement of Antibacterial Activity. The antibacterial behaviour of the synthesized materials was examined using the Mueller-Hinton agar well diffusion method against one gram-positive bacteria (Staphylococcus aureus) and one gram-negative bacteria (Escherichia coli). To distribute the bacterial cultures (fresh) over the plates, the spread plate technique was utilized whereas the prepared medium was placed into petri plates. Discs with a diameter of $6 \mathrm{~mm}$ and a weight of $20 \mathrm{~g}$ were distributed onto the petri plates and gently pressed to make sure that the discs have adhered with agar. A disc consisting of gentamicin, a typical antibiotic, was also inserted on every plate for comparison. The prepared plates were kept for incubation for 24 hours at 35 degrees Celsius. The spread diameter of the inhibition zone around the paper discs was estimated and denoted in millimeters after the incubation period.

\section{Results and Discussions}

3.1. Structural Research. The XRD of Sr-doped $\mathrm{ZnO}$ nanoparticles with different strontium atomic ratios is shown in Figure $1(0,3,5$, and 7 at.\%). The hexagonal wurtzite structure is represented by all of the diffraction peaks at (100), (002), (101), (102), (110), (103), and (112). Furthermore, the JCPDS card no. 36-1451 is sufficiently indexed for these diffraction peaks. There are no peaks of metallic $\mathrm{ZnO}_{2}$ or any other phases found. Furthermore, the powerful and crisp diffraction peaks indicate that the as-made nanoparticles are highly crystalline.

Using the well-known Scherrer's formula [21], the crystallite size $(D)$ of undoped and $\mathrm{Sr}$-doped $\mathrm{ZnO}$ nanoparticles is calculated.

$$
D=\frac{k \lambda}{\beta \cos \theta} .
$$

Table 1 shows the computed " $D$ " values for the wavelength of the X-ray used (1.5406), the full width at half maximum (FWHM) of the 101 plane, and the angle of diffraction. The crystallite size measured ranges from 39 to $46 \mathrm{~nm}$. The increasing incorporation of $\mathrm{Sr}$ at the $\mathrm{ZnO}$ sites, respectively, may be causing the steady declines in crystallinity of produced nanoparticles.

The formula [22] is used to obtain the lattice constants ' $a$ ' and ' $c$ '.

$$
\frac{1}{d^{2}}=\frac{4}{3}\left[\frac{h^{2}+h k+k^{2}}{a^{2}}\right]+\frac{1^{2}}{c^{2}} .
$$

The computed lattice constants ' $a$ ' and ' $c$ ' are remarkably close to the conventional values of strontium-doped $\mathrm{ZnO}$ nanoparticles up to 7 at.\%. The substitution of strontium increased the particle size because $\mathrm{Sr}^{2+}(1.12 \AA)$ has a larger ionic radius than $\mathrm{Zn}^{2+}(0.74 \AA)$. The further increase in doping concentration slightly reduced the overall 


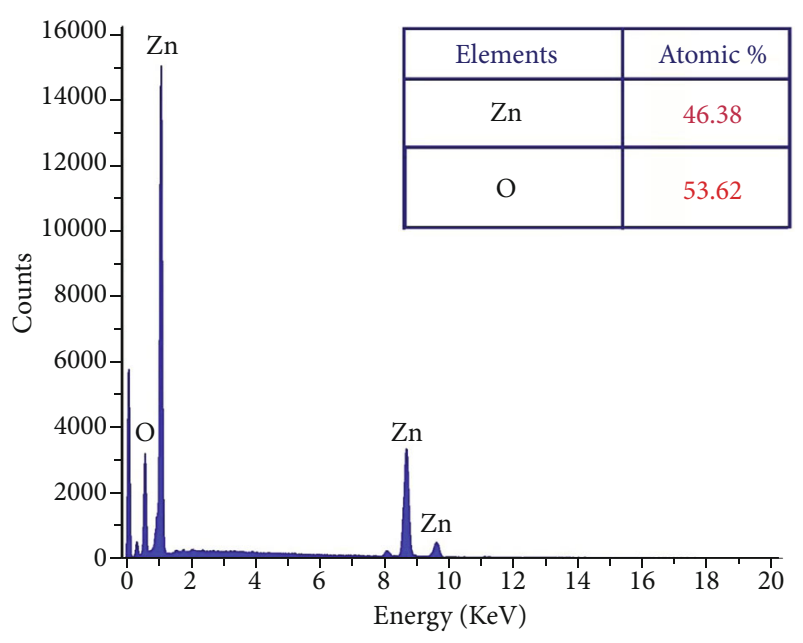

(a)

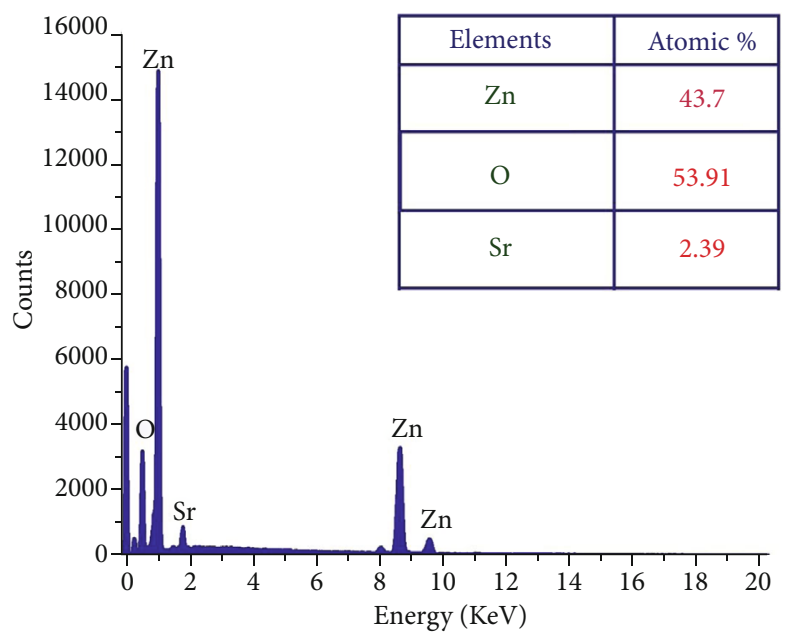

(c)

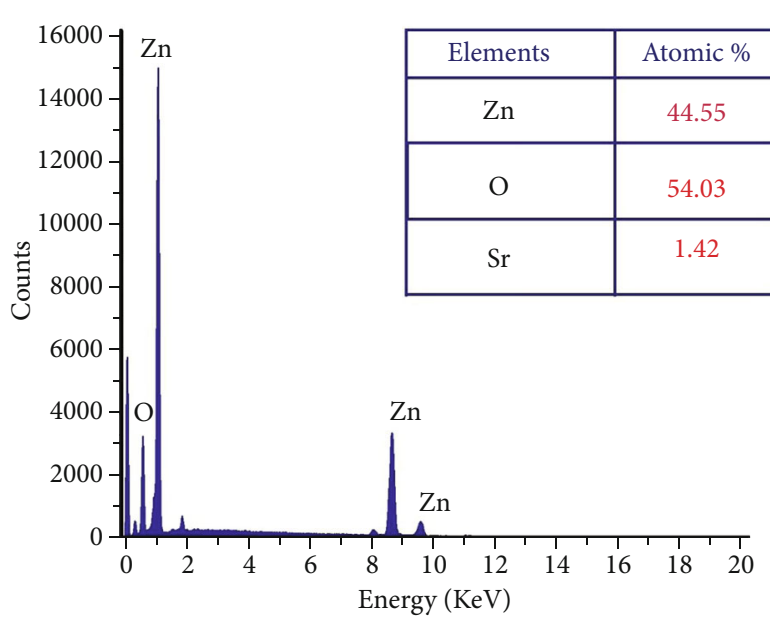

(b)

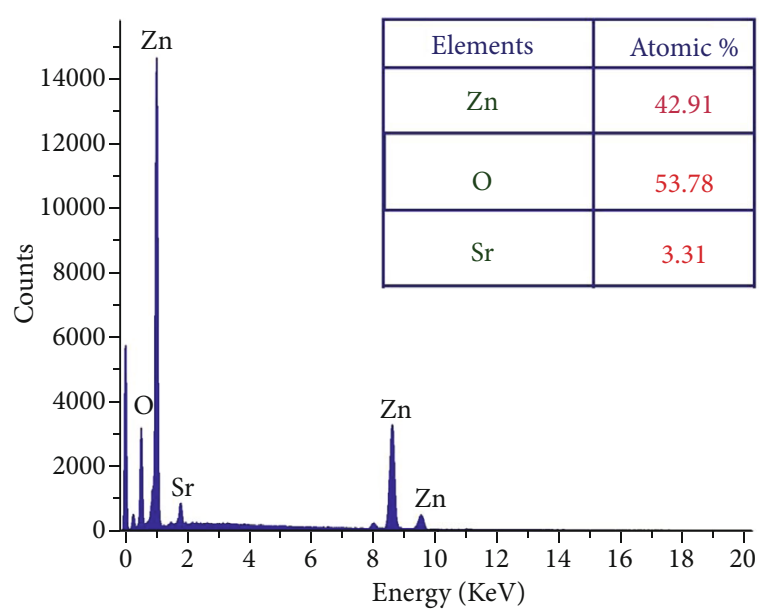

(d)

Figure 3: EDX profile of (a) undoped and (b) Sr- (3\%) doped ZnO nanoparticles, (c) Sr- (5\%) doped ZnO nanoparticles, (d) Sr- (5\%) doped $\mathrm{ZnO}$ nanoparticles.

particle size. This increase in the particle size indicated that the dopant has been entered into the host lattice effectively. The $C$ was decreased and the particle size increased for Sr (3 at.\%). For Sr (5 at.\% and 7 at.\%), the $C$ was increased and the particle size reduced. Ouhaibi et al. observed in their research that the particle size was increased up to Sr of 3 at.\% and reduced for further incorporation of $\mathrm{Sr}$ ions [23].

3.2. Analysis of Morphology and Elements. The surface morphology of $\mathrm{ZnO}$ and $\mathrm{Sr}$-doped $\mathrm{ZnO}$ nanoparticles is shown in Figure 2. The FESEM pictures reveal a uniform and highly crystalline $\mathrm{ZnO}$ nanostructure. The top surface of undoped $\mathrm{ZnO}$ nanoparticles had a typical hexagonal cross section (Figure 2(a)). The addition of different concentrations of strontium (3, 5, and 7 at.\%) resulted in the development of material on the nanoparticles. These generated nanoparticles are consistently dispersed over the surface and have high communication between them, as seen in the TEM image (Figure 2(e)). As a result, doping leads to a remarkable impact on the grain size of the $\mathrm{ZnO}$ nanoparticles, resulting in changes in morphology.

The surface morphology was changed due to Sr doping in the $\mathrm{ZnO}$ lattice. The $\mathrm{ZnO}$ and $\mathrm{Sr}$ particles were highly accumulated at the surface and formed a cluster near the surface, and the size was increased. With further addition of $\mathrm{Sr}$, the cluster size was decreased. The increase in crystallite size indicates that the dopant Sr has been substituted in $\mathrm{Zn}^{2+}$ sites. The incorporation of $\mathrm{Sr}$ produces some distortion on the lattice and leads to some supplementary defects. These are responsible for the change in morphology.

The presence of $\mathrm{Zn}, \mathrm{O}$, and $\mathrm{Sr}$ atoms in produced nanoparticles is indicated by the EDX spectra (Figures 3(a)-3(d)). The highly intense $\mathrm{Zn}$ and $\mathrm{O}$ peaks were found, indicating that the nanoparticles were mostly $\mathrm{ZnO}$ with a few impurities. The at.\% value of each element present in the table samples was listed as a table in each figure. All the elements' presence ratios are matched well with the targeted stoichiometry ratio. From the EDX spectra, the presence of dopant ions in the host material is proven. 


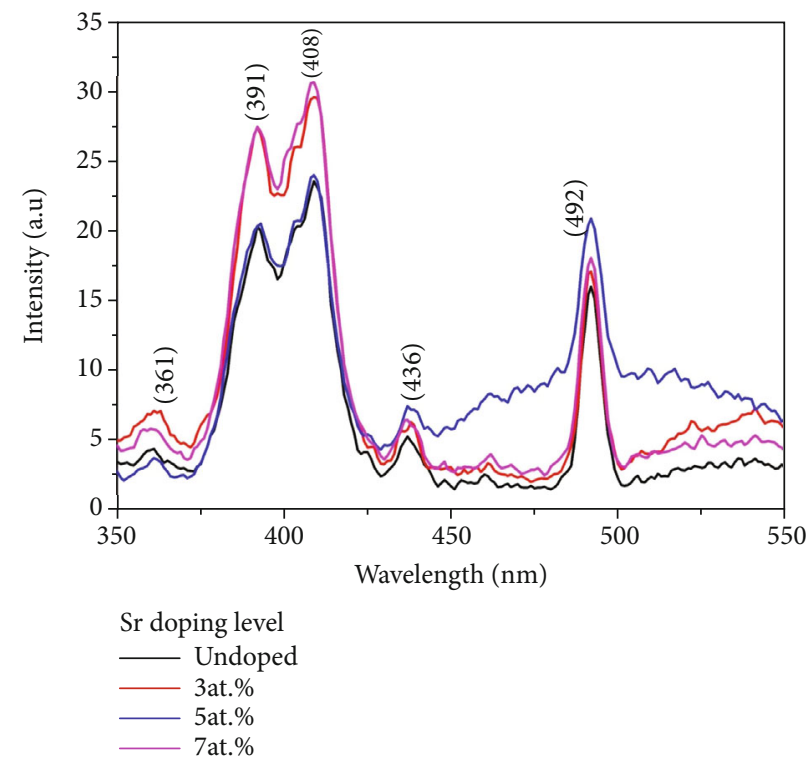

FIgure 4: PL intensities of undoped and Sr-doped $\mathrm{ZnO}$ nanoparticles.

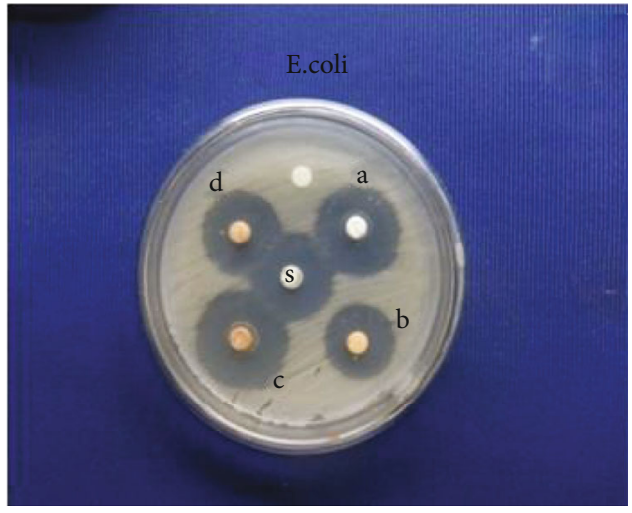

(i)

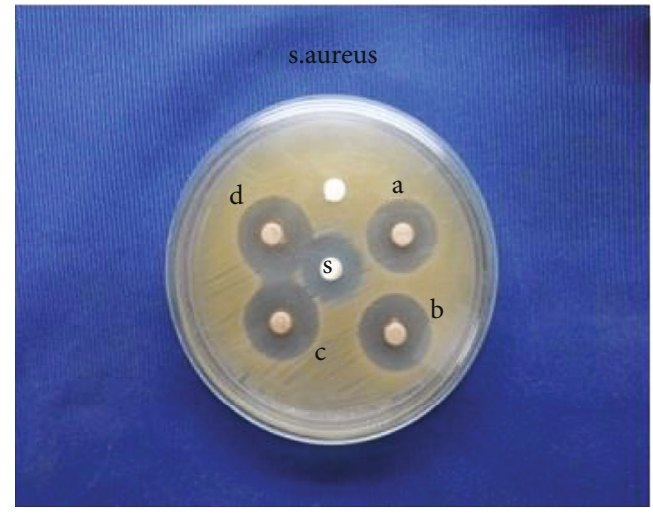

(ii)

Figure 5: Antibacterial activity of $\mathrm{ZnO}: \mathrm{Sr}$ nanoparticles against (i) E. coli and (ii) S. aureus: (a) $\mathrm{ZnO}: \mathrm{Sr}(0 \%)$; (b) $\mathrm{ZnO}: \mathrm{Sr}(3 \%)$; (c) $\mathrm{ZnO}: \mathrm{Sr}$ (5\%); (d) $\mathrm{ZnO}: \mathrm{Sr}(5 \%)$.

3.3. Photoluminescence of $\mathrm{ZnO}: \mathrm{Sr}$ Nanoparticles. $\mathrm{ZnO}$ and Sr-doped $\mathrm{ZnO}$ nanoparticles had photoluminescence spectra that were excited at $325 \mathrm{~nm}$ (Figure 4). At $408 \mathrm{~nm}(2.922 \mathrm{eV}$ ), the spectrum reveals a strong peak violet emission. The product's emission peak positions are nearly unchanged, as can be shown. Shown is an intrinsic characteristic of Srdoped $\mathrm{ZnO}$ nanoparticles themselves when excited at $325 \mathrm{~nm}$. Excitonic recombination is responsible for the UV emission at $361 \mathrm{~nm}$, which indicates the near band edge emission of $\mathrm{ZnO}[24,25]$. The purple-blue emission around $436 \mathrm{~nm}$ is most likely due to a neutral oxygen vacancy defect's triplet to ground transition [26]. The presence of impurity ( $\mathrm{Sr}$ ) atoms in the host $\mathrm{ZnO}$ matrix, as well as zinc and oxygen vacancies, is most likely responsible for the violet emission at $408 \mathrm{~nm}$. Furthermore, doping $\mathrm{Sr}$ ions can result in larger active defects in the $\mathrm{ZnO}$ lattice, which can enhance the photocatalytic activity of the Sr-doped $\mathrm{ZnO}$ crystals in the visible region [27].
A series of visible emissions have also been reported in the wavelength range of 400 to $600 \mathrm{~nm}$. Various types of intrinsic defects, including defect states, interstitials, and oxygen vacancies, can all be blamed for visual emission. The incorporation of $\mathrm{Sr}$ ions can create more active defect sites in the $\mathrm{ZnO}$ host lattice, which absorbs more visible light. This produces better photocatalytic activity of the Sr-doped $\mathrm{ZnO}$ crystallites in the visible range. Surface imperfections caused blue emission at $436 \mathrm{~nm}$ and green-blue emission at $492 \mathrm{~nm}$. As a result, the increased PL emission implies that the flaws that exist in $\mathrm{Sr}$-doped $\mathrm{ZnO}$ improve photocatalytic activity.

3.4. Antibacterial Activity. Sr-doped $\mathrm{ZnO}$ nanoparticles were tested for antibacterial activity against one gram-positive pathogen (E. coli) and one gram-negative pathogen (S. aureus), which are the most common bacteria that cause dihedral illness. The antibacterial activity of these nanoparticles is stronger 


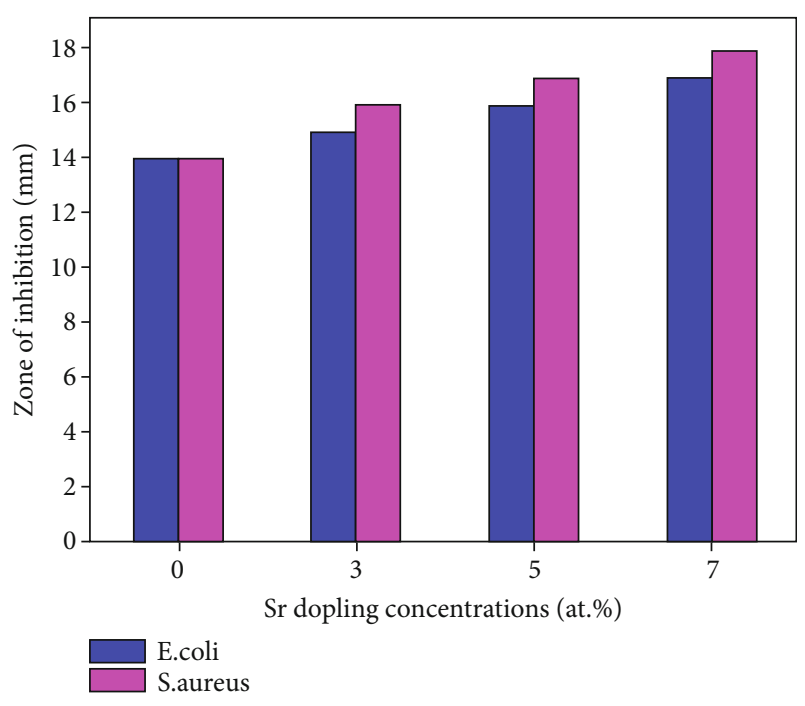

Figure 6: Variation in the zone of inhibition caused by Sr-doped $\mathrm{ZnO}$ nanoparticles.

in S. aureus and E. coli (Figure 5). Bacterial growth is inhibited by atomic percent in the presence of nanoparticles at specific concentrations. Surprisingly, this amount varies greatly depending on the size of the nanoparticles. Figure 6 shows the measured inhibitory zone diameters of the samples. Gram-positive bacteria possess a thicker cell wall and a single cytoplasmic membrane with many layers of peptidoglycan polymers [28] (20-80 nm). The gram-negative bacterial wall, on the other hand, is made up of two cell membranes and a plasma membrane with a thin layer of peptidoglycan [29] that is $7-8 \mathrm{~nm}$ thick. Nanoparticles with sizes in this range can easily pass through the peptidoglycan, making them vulnerable to destruction. The bacterial concentration was found to decrease as the concentration of Sr-doped $\mathrm{ZnO}$ was increased. The growth of E. coli and $S$. aureus was suppressed more at a concentration of $7 \%$ Sr-doped $\mathrm{ZnO}$.

These $\mathrm{ZnO}$ nanoparticles have a biocidal impact and are effective at delaying bacterial development. These findings could lead to significant technologies in the future, such as antibacterial systems and medical equipment. The antibacterial behaviour of the nanostructure may be ascertained to two possible mechanisms: (i) the generation of increased levels of Reactive Oxygen Species (ROS), such as superoxide anion $\left(\mathrm{O}_{2}^{-}\right)$, hydroxyl radical $\left({ }^{-} \mathrm{OH}\right)$, and hydrogen peroxide $\left(\mathrm{H}_{2} \mathrm{O}_{2}\right)$, and (ii) the deposition of nanoparticles on the surface of bacteria in the cytoplasm region, causing cellular function disruption [30].

$\mathrm{UV}$ and visible light can both activate $\mathrm{ZnO}$ with a crystal flaw. When an appropriate photon strikes $\mathrm{ZnO}$, an electron is stimulated from the valance band to the conduction band, leaving a hole in the valance band. Superoxide anion radicals are formed when an electron in the conduction band combines with dissolved oxygen molecules $\left(\mathrm{O}_{2}^{-}\right)$. The valence band hole separated the water molecule into $\mathrm{OH}$ - and $\mathrm{H}^{+}$ ions. $\mathrm{HO}_{2}$ radicals are formed when superoxide anion radicals $\left(\mathrm{O}_{2}^{-}\right)$combine with $\mathrm{H}^{+}$. $\mathrm{H}^{+}$reacts with the $\mathrm{HO}_{2}$ radicals to form the $\mathrm{H}_{2} \mathrm{O}_{2}$ molecule. The $\mathrm{H}_{2} \mathrm{O}_{2}$ can easily enter the cell membrane, killing the bacteria.
The presence of $\mathrm{Sr}$ in $\mathrm{ZnO}$ structure increased the antibacterial activity against both gram-positive Staphylococcus aureus and gram-negative Escherichia coli. The increment order is the function of the doping ratio of Sr. The maximum zone inhibition was received for the highest doping concentration of $\mathrm{Sr}(7 \%)$.

AL-Jawad et al. observed a similar enhancement of antibacterial activity against $S$. aureus and E. coli in Ag-doped $\mathrm{ZnO}$ thin films [31]. Fe-doped $\mathrm{ZnO}$ thin films also exhibited a better antibacterial response under UV light irradiation against $S$. aureus and E. coli [32].

The Sr-doped $\mathrm{ZnO}$ particles are allowed by the cell wall of $E$. coli for an electrostatic interaction; this might cause a breakdown of the membrane barrier, and ultimately its cell got damaged. This electrostatic interaction is more at gram-positive bacteria than at gram negative-bacteria. A similar effect is produced in $S$. aureus bacteria also. According to XRD particle size calculation, higher doping percentage of $\mathrm{Sr}$ reduced the overall size of the particles. These small-sized particles can enter more numbers, and the cell damage is also proportionately increased [33].

\section{Conclusion}

A simple soft chemical approach was used to successfully produce both undoped and $\mathrm{Sr}$-doped $\mathrm{ZnO}$ nanoparticles. The impacts of $\mathrm{Sr}$ on $\mathrm{ZnO}$ nanoparticles were investigated in terms of structural, morphological, and optical properties. The nanoscale portion of the prepared samples had a hexagonal wurtzite structure without any impurities or secondary phases, according to XRD data. Physical factors such as crystal size have been found to decrease when $\mathrm{Sr}$ is added to the $\mathrm{ZnO}$ matrix. The EDX analysis showed the presence of $\mathrm{Sr}$ content in the $\mathrm{ZnO}$. The FESEM study determined the change in surface morphology with doping. For the doped nanoparticles, the PL spectrum indicated a high UV emission around the near band edge region (NBE) and defect states encountered in visible emissions. These findings suggested that $\mathrm{Sr}$-doped $\mathrm{ZnO}$ nanoparticles could be useful in optoelectronic devices and photocatalytic degradation of organic molecules in the future. The Sr-doped $\mathrm{ZnO}$ nanoparticles produced an enhanced antibacterial activity against E. coli and S. aureus. Hence, these materials will be useful for biological applications.

\section{Data Availability}

Data can be made available from the corresponding author on reasonable request.

\section{Conflicts of Interest}

The authors declare that they have no conflict of interest.

\section{References}

[1] J. V. Foreman, J. Li, H. Peng, S. Choi, H. O. Everitt, and J. Liu, "Time-resolved investigation of bright visible wavelength luminescence from sulfur-doped $\mathrm{ZnO}$ nanowires and micropowders," Nano Letters, vol. 6, p. 1126, 2006. 
[2] A. B. Djurišić and Y. H. Leung, "Optical properties of $\mathrm{ZnO}$ nanostructures," Small, vol. 2, p. 944, 2006.

[3] J. V. Foreman, H. O. Everitt, J. Yang, and J. Liu, "Influence of temperature and photoexcitation density on the quantum efficiency of defect emission in ZnO powders," Applied Physics Letters, vol. 91, article 011902, 2007.

[4] J. Wojnarowicz, T. Chudoba, and W. Lojkowski, “A review of microwave synthesis of zinc oxide nanomaterials: reactants, process parameters and morphologies," Nanomaterials, vol. 10, p. 1086, 2020.

[5] J. Zhou, Q. Liu, W. Feng, Y. Sun, and F. Y. Li, "Upconversion luminescent materials: advances and applications," Chemical Reviews, vol. 115, p. 395, 2015.

[6] G. G. Li, Y. Tian, Y. Zhao, and J. Lin, "Recent progress in luminescence tuning of $\mathrm{Ce}^{3+}$ and $\mathrm{Eu}^{2+}$-activated phosphors for pcWLEDs," Chemical Society Reviews, vol. 44, p. 8688, 2015.

[7] K. Kanagamani, P. Muthukrishnan, A. Kathiresan, K. Shankar, P. Sakthivel, and M. Ilayaraja, "Detoxication and theranostic aspects of biosynthesised zinc oxide nanoparticles for drug delivery,” Acta Metall. Sin. (Engl. Lett.), vol. 34, no. 729, 2021.

[8] L. W. Lin, X. Y. Sun, Y. Jiang, and Y. H. He, "Sol-hydrothermal synthesis and optical properties of $\mathrm{Eu}^{3+}, \mathrm{Tb}^{3+}$ - codoped one dimensional strontium germanate full color nano-phosphors," Nanoscale, vol. 5, p. 12518, 2013.

[9] X. M. Zhang, M. Y. Lu, Y. Zhang, L. J. Chen, and Z. L. Wang, "Fabrication of a high-brightness blue-light-emitting diode using a ZnO-nanowire array grown on $\mathrm{p}-\mathrm{GaN}$ thin film," Advanced Materials, vol. 21, p. 2767, 2009.

[10] P. H. Yeh, Z. Li, and Z. L. Wang, "Schottky-gated probe-free $\mathrm{ZnO}$ nanowire biosensor," Advanced Materials, vol. 21, p. 4975, 2009.

[11] B. Weintraub, Y. Wei, and Z. L. Wang, "Optical fiber/nanowire hybrid structures for efficient three-dimensional dyesensitized solar cells," Angewandte Chemie. International Edition, vol. 48, p. 8981, 2009.

[12] Z. L. Wang and J. Song, "Piezoelectric nanogenerators based on zinc oxide nanowire arrays," Science, vol. 312, p. 242, 2006.

[13] X. Wang, J. Song, J. Liu, and Z. L. Wang, "Direct-current nanogenerator driven by ultrasonic waves," Science, vol. 316, no. 5821, pp. 102-105, 2007.

[14] S. Xu, Y. Qin, C. Xu, Y. Wei, R. Yang, and Z. L. Wang, "Selfpowered nanowire devices," Nature Nanotechnology, vol. 5, p. 366, 2010.

[15] K. M. Lee, C. W. Lai, K. S. Ngai, and J. C. Juan, "Recent developments of zinc oxide based photocatalyst in water treatment technology: a review," Water Research, vol. 88, p. 428, 2016.

[16] C. Cheng, A. Amini, C. Zhu, Z. L. Xu, H. S. Song, and N. Wang, "Enhanced photocatalytic performance of $\mathrm{TiO}_{2}-\mathrm{ZnO}$ hybrid nanostructures," Scientific Reports, vol. 4, p. 4181, 2014.

[17] C. G. Tian, Q. Zhang, A. P. Wu et al., "Cost-effective largescale synthesis of $\mathrm{ZnO}$ photocatalyst with excellent performance for dye photodegradation," Chemical Communications, vol. 48, p. 2858, 2012.

[18] D. Andeen, L. Loeffler, N. Padture, and F. F. Lange, "Crystal chemistry of epitaxial $\mathrm{ZnO}$ on $\left(\begin{array}{lll}1 & 1 & 1\end{array}\right) \mathrm{MgAl}_{2} \mathrm{O}_{4}$ produced by hydrothermal synthesis," Journal of Crystal Growth, vol. 259, p. 103, 2003.

[19] K. Byrappa, A. S. Dayananda, C. P. Sajan et al., "Hydrothermal preparation of $\mathrm{ZnO}: \mathrm{CNT}$ and $\mathrm{TiO}_{2}$ : CNT composites and their photocatalytic applications," Journal of Materials Science, vol. 43 , p. 2348, 2008.
[20] A. T. Ravichandran, R. Karthick, A. R. Xavier, R. Chandramohan, and S. Mantha, "Influence of Sm doped $\mathrm{ZnO}$ nanoparticles with enhanced photoluminescence and antibacterial efficiency," Journal of Materials Science: Materials in Electronics, vol. 28, no. 9, pp. 6643-6648, 2017.

[21] P. Sakthivel, K. Kavi Rasu, A. Sivakami, P. Muthukrishnan, and G. K. D. Prasanna Venkatesan, "Band gap tailoring, structural and optical features of MgS nanoparticles: influence of $\mathrm{Ag}^{+}$ions," Optik, vol. 236, p. 166544, 2021.

[22] K. Saravanakumar, R. K. Sankaranarayanan, P. Sakthivel, K. Catherine, and S. Pushpa, "Microwave assisted green synthesis of zinc oxide nanoparticles for biological applications," AIP Conf. Proc., vol. 2270, no. 11003, 2020.

[23] A. Ouhaibi, M. Ghamnia, M. A. Dahamni, V. Heresanu, C. Fauquet, and D. Tonneau, "The effect of strontium doping on structural and morphological properties of $\mathrm{ZnO}$ nanofilms synthesized by ultrasonic spray pyrolysis method," Journal of Science: Advanced Materials and Devices, vol. 3, no. 1, pp. 29-36, 2018.

[24] K. Saravanakumar, P. Sakthivel, and R. K. Sankaranarayanan, "Influence of $\mathrm{Sn}^{4+}$ ion on band gap tailoring, optical, structural and dielectric behaviors of $\mathrm{ZnO}$ nanoparticles," Spectrochimica Acta Part A: Molecular and Biomolecular Spectroscopy, vol. 267, no. 120484, 2022.

[25] A. Krishnamoorthy, P. Sakthivel, I. Devadoss, and V. A. Rajathi, "Role of Bi3+ ions on structural, optical, photoluminescence and electrical performance of Cd0. 9-xZn0. 1BixS QDs," SN Applied Sciences, vol. 3, no. 7, pp. 1-2, 2021.

[26] Y. C. Her, J. Y. Wu, Y. R. Lin, and S. Y. Tsai, "Low temperature growth and blue luminescence of $\mathrm{SnO}_{2}$ nanoblades," Applied Physics Letters, vol. 89, article 043115, 2006.

[27] M. A. Mahmood, M. T. Z. Myint, T. Bora, and J. D. S. Baruah, "Enhanced visible light photocatalysis through fast crystallization of zinc oxide nanorods," Beilstein journal of nanotechnology, vol. 1, p. 14, 2010.

[28] B. Debnath, G. Halder, and S. Bhattacharyya, "One-step synthesis, structural and optical characterization of selfassembled $\mathrm{ZnO}$ nanoparticle clusters with quench-induced defects," Science of Advanced Materials, vol. 6, no. 1160, 2014.

[29] G. Fu, P. S. Vary, and C.-T. Lin, "Anatase $\mathrm{TiO}_{2}$ nanocomposites for antimicrobial coatings," The Journal of Physical Chemistry. B, vol. 109, p. 8889, 2005.

[30] K. R. Raghupathi, R. T. Koodali, and A. C. Manna, "Sizedependent bacterial growth inhibition and mechanism of antibacterial activity of zinc oxide nanoparticles," Langmuir, vol. 27, p. 4020, 2011.

[31] A. L.-J. SM, S. H. Sabeeh, A. A. Taha, and H. A. Jassim, "Studying structural, morphological and optical properties of nanocrystalline $\mathrm{ZnO}$ : Ag films prepared by sol-gel method for antimicrobial activity," Journal of Sol-Gel Science and Technology, vol. 87, no. 2, pp. 362-371, 2018.

[32] S. M. Al-Jawad, S. H. Sabeeh, A. A. Taha, and H. A. Jassim, "Synthesis and characterization of $\mathrm{Fe}-\mathrm{ZnO}$ thin films for antimicrobial activity," Surface review and letters, vol. 26, no. 5, p. 1850197, 2019.

[33] K. Ravichandran, N. Chidhambaram, T. Arun, S. Velmathi, and S. Gobalakrishnan, "Realizing cost-effective $\mathrm{ZnO}$ :Sr nanoparticles@graphene nanospreads for improved photocatalytic and antibacterial activities," RSC Advances, vol. 6, p. 67575, 2016. 